\title{
EFFORT-REWARD IMBALANCE AT WORK IS PREDICTED BY TEMPORAL AND ENERGETIC CHARACTERISTICS OF BEHAVIOR: A POPULATION-BASED STUDY
}

TAINA HINTSA ${ }^{1}$, MIRKA HINTSANEN ${ }^{2,1}$, MARKUS JOKELA ${ }^{1}$, LAURA PULKKI-RÅBACK ${ }^{1}$, and LIISA KELTIKANGAS-JÄRVINEN ${ }^{1}$

${ }^{1}$ University of Helsinki, Helsinki, Finland

Institute of Behavioural Sciences (IBS)

${ }^{2}$ University of Helsinki, Helsinki, Finland

Helsinki Collegium for Advanced Studies

\begin{abstract}
Objective: Personality dispositions may influence perceptions of work stress. The paper examines the relationship between temperament in terms of Strelau's Regulative Theory of Temperament and the effort-reward imbalance and its components. Material and Methods: There were 890 participants $(360$ men) aged 37.9 years on average. Temperament traits of briskness and perseveration (temporal characteristics of behavior), sensory sensitivity, emotional reactivity, endurance and activity (energetic characteristics of behavior) were measured by Strelau \& Zawadzki's Formal Characteristics of BehaviorTemperament Inventory (FCB-TI) in 1997 and 2001. Effort and reward at work were assessed with the original effortreward imbalance (ERI) questionnaire of 2007. Results: Higher ERI at work was predicted by higher emotional reactivity, higher perseveration, lower briskness, and lower endurance. Higher effort and lower rewards at work were predicted by higher perseveration and lower endurance. The FCB-TI temperament characteristics accounted for $5.2 \%, 4.8 \%$ and $6.5 \%$ of the variance in the ERI, effort and reward, respectively. Lower emotional reactivity, lower perseveration, higher briskness and higher endurance predicted higher esteem at work, job promotion and job security. Conclusions: Individual differences in arousability, reflected in temporal and energetic characteristics of behavior, may predispose to or to protect from an effort-reward imbalance at work. Individual differences should be acknowledged in work stress prevention and developing interventions.
\end{abstract}

Key words:

Effort-reward imbalance, Emotional reactivity, Regulative Theory of Temperament, Temperament, Work stress

\section{INTRODUCTION}

Work is the prerequisite for an income as well as an important source of wellbeing. Although work can be satisfying and rewarding, it can also be a source of stress. Employees can be encumbered with both psychological and physical demands at work. One of the leading scientific work stress theories, e.g. Siegrist's effort-reward imbalance (ERI) model which is based on social exchange theory, assumes that high efforts and low rewards are likely to elicit work stress in the majority of employees [1-3]. Efforts refer to

TH was supported by Ella and Georg Ehrnrooth Foundation and Academy of Finland (project 132729); MH was supported by Emil Aaltonen Foundation, Ella \& Georg Ehrnrooth Foundation, and Research Funds of the University of Helsinki; LP-R was supported by Academy of Finland (project no 123621).

Received: July 2, 2012. Accepted: February 13, 2013.

Corresponding author: T. Hintsa, IBS, University of Helsinki, PO Box 9, FIN-00014 University of Helsinki, Finland (e-mail: taina.hintsa@helsinki.fi). 
work pressures and rewards to esteem, salary and career continuity. If effort is not rewarded, an effort-reward imbalance condition may occur, and is assumed to induce work stress in the majority of employees [2]. The main stream of work stress research has previously focused on the consequences of work stress $[1,4,5]$. However, individual characteristics may contribute to perception of effort and rewards at work $[6,7]$.

Psychological stress is assumed to be caused by an imbalance between individual capacities and environmental demands. A stress state includes negative emotions, and stress brings on physiological and biochemical changes in the body [8,9]. There are individual differences both in perceptions of stress, i.e. appraisal of stressors and stress management [10,11], in physiological stress reactivity [12] and in recovering from stress [13]. Individual variation of the experience of stress may be related to differences in temperament $[11,14,15]$. Temperament refers in general to biologically-based, early emerging and relatively stable individual dispositions that reflect the reactivity to environmental stimuli, and the behavioural-emotional regulation of such reactivity [15]. Temperament traits are assumed to constitute antecedent conditions that influence subsequent conditions, and therefore, can be considered as moderators of all stress phenomena [15]. Temperament characteristics may predispose individuals to react differently in stressful encounters [7,10,11,16,17]. In arousaloriented theories of temperament (e.g. The Regulative Theory of Temperament by Strelau) temperament traits are assumed to be stress moderators at extreme levels of stimulation [15]. Reactivity has a physiological basis and temperament traits are assumed to be determined by the level of arousal and their neurobiochemical mechanisms, and to be the principal moderator of the stimulating and temporal value of behaviours and reactions [18]. There are individual differences in arousability which, in turn, influence the preferred style of activity and effectiveness of performance [18].
The RTT model defines temperament as a collection of basic, relatively stable personality traits that apply mainly to the temporal and energetic characteristics of reactions and behavior [18]. Temperament is postulated to consist of six formal characteristics of behaviour that represent individual differences in temporal and energetic aspects of behaviour $[19,20]$. The temporal and energetic characteristics of behavior participate in the regulation of stimulation and the level of arousal which is disrupted in stressful situations [18]. Thus, temperament is postulated to participate in the regulation of individual-environment interaction, and is assumed to play an adaptive role in this process [15]. The temporal characteristics of behavior refer to the speed and tempo of reactions in regard to changes in the environment, and they are measured by the traits of briskness and perseveration. Briskness (BR) is a tendency to react quickly, to keep a high tempo in activities, and to shift from one behavior to another when necessary. Perseveration (PE) refers to continuation and repetition of behavior after cessation of stimuli requiring this behavior. The energetic characteristics of behavior represent physiological individual differences that define the energy level of the organism and temporal characteristics of behavior, the speed, tempo and mobility of nervous processes. The energetic aspects of behaviour refer to behaviour under stressors and risk-taking activity, and are measured by the traits of sensory sensitivity, emotional reactivity, endurance and activity. Sensory sensitivity (SS) is an ability to react to low value sensory stimuli. Emotional reactivity (ER) denotes intensive reactions to emotion-generating stimuli, expressed in low endurance of emotional stimuli and high emotional sensitivity. Endurance (EN) is an ability to react adequately in highly stimulating situations or in conditions of extensive environmental stimulation, i.e. in situations demanding prolonged activity. Activity (AC) refers to undertaking behaviors of high stimulative value. 
There is some previous evidence on the influence of personality and temperament on work stress. Of the Big Five personality traits, higher neuroticism has been linked with higher work stress [21,22]. Regarding work stress indexed by ERI at work, higher eagerness-energy and hard-driving personality have been shown to predict higher ERI and higher effort at work [6]. Previously it has been reported that higher harm avoidance and lower novelty seeking, defined by Cloninger's temperament theory, predict perceptions of work stress [16]. High negative emotionality and activity, as defined by Buss and Plomin's temperament theory [23,24], have been shown to predict high perceived ERI and low rewards at work [7]. As yet, however, there is no information on associations between temperament characteristics in terms of the Regulative Theory of Temperament (Strelau) and ERI.

The aim of our study was to examine whether RTT temperament traits, i.e. briskness, perseveration, sensory sensitivity, emotional reactivity, endurance and activity, predict perceived ERI and its components (effort and rewards). Thus far, the associations between RTT temperament traits and perceived ERI have not been studied. Based on previous evidence on the relationship between RTT temperament traits and stress [18,21], it is hypothesized that higher emotional reactivity, higher perseveration, lower briskness, lower endurance and lower activity predict higher ERI. The previous literature being so scarce, no hypothesis is proposed for sensory sensitivity and components of ERI.

\section{MATERIAL AND METHODS}

\section{Subjects}

The Young Finns Study (YFS) is an epidemiological, prospective follow-up study of a Finnish population [25,26]. A total of 3596 participants (aged 3 to 18-years) were at baseline in 1980. After 27 years of follow-up (in 2007), 61.2\% of the original cohort was still participating in the study [27].
All participants gave written informed consent, and the study was approved by the local ethics committees.

The present subjects participated in the follow-ups of the Young Finns study in 1997, 2001 and 2007. It was required that participants have full information on all study variables. In 2007, 1585 participants reported working full time, and of those, 1574 reported effort and rewards at work in 2007. Of these participants, 890 participants had full data on age, gender, education, occupation and temperament traits in 1997 and 2001. The participants were on average 37.9 years old $(\mathrm{SD}=4.99)$ in 2007 , and $40.6 \%$ of the participants were men $(\mathrm{N}=360)$.

\section{Measures}

Temperament

Temperament was assessed with the self-reported Formal Characteristics of Behavior Temperament Inventory (FCB-TI) by Strelau and Zawadzki [19,20], which includes 120 items (each trait comprising 20 items) rated in a yes $=1$, no $=0$ format comprised of temperament traits of briskness (e.g. "I am generally slower than others in carrying out my professional and domestic duties" reversed, "It's difficult for me to retain former proficiency if I have not practiced for a long time" reversed); perseveration (e.g. "When under stress I tend to repeat certain movements, e.g. tidying my hair, adjusting my clothes, rubbing my face", "After failures it takes a long time for me to pull myself together"); sensory sensitivity ("I can only smell strong smells" reversed, "The only spices I can taste while having a meal are the hot ones"); emotional reactivity ("I often breakdown in difficult moments", "I tend to make mistakes when working under pressure"); endurance ("I easily get tired if I have to work at something intensive" reversed, "I can continue working regardless of being tired"), and activity ("My social life is very active", "I try to organize my holidays to experience as much as possible"). The reliabilities of the FCB-TI scale temperament traits in 1997 and 2001 ranged from 0.7 to 0.8 (Cronbach's $\alpha$ ). 
Stability of RTT temperament traits from 1997 to 2001 ranged from $r=0.60(\mathrm{SS})$ to $r=0.76(\mathrm{ER})$. A mean score of two measurement points (1997 and 2001) was calculated to yield an index of temperament.

\section{Effort-reward imbalance}

In 2007, efforts and rewards at work were measured by the original scale [2]. The effort scale consisted of five items $(\alpha=0.76)$ and reward scale of 11 items $(\alpha=0.82)$. The components of rewards consisted of esteem (5 items, $\alpha=0.85$ ), job promotion ( 4 items, $\alpha=0.61$ ), and job security ( 2 items, $\alpha=0.62$ ). Effort-reward imbalance was calculated as ratio between effort and reward as suggested by Siegrist [2]. A logarithmic transformation was then made for the effort-reward imbalance scale to correct for skewness and curtosis.

\section{Control variables}

The participants' education was reported by degree level in 2007. There were three occupational groups based on Central Statistical Office of Finland in 2001 and in 2007: 1) manual, 2) lower non-manual and 3) upper non-manual. Entrepreneurs were classified into these occupational groups according to level of education, that is, low = manual, intermediate $=$ lower non-manual and high $=$ upper non-manual.

\section{Statistical analyses}

The associations between temperament traits, effort, reward and ERI were examined by a series of linear regression analyses controlling for age, sex, education and occupation. In order to obtain a percentage of the degree to which temperament traits together account for the variation on effort, reward and effort-reward imbalance, analyses with all temperament traits included were run. There were no significant sex-temperament interactions on ERI or its components ( $p$-values $>0.05$ ), and therefore women and men were combined in the analyses.

\section{RESULTS}

The descriptive statistics of the sample are shown in Table 1. Attrition analyses showed that the included participants did not differ from excluded subjects in ERI, effort, reward, sensory sensitivity or activity (all p-values $>0.05$ ). The participants were older (37.9 vs. 37.3, $\mathrm{p}<0.001$ ), and more educated (4.2 vs. 3.9, p < 0.001), had higher occupational status (2.2 vs. 2.0, $\mathrm{p}<0.001)$, scored lower on perseveration ( 0.54 vs. $0.58, \mathrm{p}<0.001)$ and emotional reactivity ( 0.40 vs. $0.44, p=0.001)$, and higher on briskness (0.81 vs. $0.79, \mathrm{p}=0.001)$ and endurance $(0.56$ vs. $0.51, \mathrm{p}<0.001)$ than the excluded subjects.

Table 2 presents the correlations between the study variables. Higher emotional reactivity was associated with lower level of education and lower occupational status. Higher activity was related to higher level of education and occupational status. Briskness and endurance correlated negatively, and perseveration, emotional reactivity and activity positively with ERI. Effort correlated positively with perseveration and activity, and negatively with endurance. Rewards were positively linked with briskness, endurance and activity, and negatively with perseveration and emotional reactivity.

The results of the linear regression analyses are presented in Table 3. They showed that higher perseveration and emotional reactivity predicted a higher effortreward imbalance at work. Higher briskness and endurance predicted a lower effort-reward imbalance. Higher perseveration and activity, and lower endurance predicted higher effort at work. Temperament was related to rewards and its components so that higher briskness, endurance and activity, and lower perseveration and emotional reactivity predicted higher rewards and its components (esteem, job promotion and job security). Higher activity predicted perceptions of job promotion possibilities and job security. Sensory sensitivity was not related to ERI or its components. 
Table 1. Descriptives of the study sample

\begin{tabular}{|c|c|c|c|c|c|}
\hline \multirow{2}{*}{ Variable } & \multicolumn{5}{|c|}{ Study participants [N = 890] } \\
\hline & range & $\mathrm{M}$ & $\mathrm{SD}$ & $\mathrm{n}$ & $\%$ \\
\hline \multicolumn{6}{|l|}{ Demographics in 2007} \\
\hline age & $30-45$ & 37.91 & 4.99 & & \\
\hline \multicolumn{6}{|l|}{ gender } \\
\hline women & & & & 530 & 59.6 \\
\hline men & & & & 360 & 40.4 \\
\hline \multicolumn{6}{|l|}{ education } \\
\hline comprehensive & & & & 23 & 2.6 \\
\hline upper secondary school & & & & 28 & 3.2 \\
\hline vocational school & & & & 272 & 30.6 \\
\hline college level education & & & & 211 & 23.7 \\
\hline higher vocational diploma & & & & 141 & 15.8 \\
\hline academic & & & & 215 & 24.2 \\
\hline \multicolumn{6}{|l|}{ occupation } \\
\hline manual & & & & 269 & 30.2 \\
\hline lower non-manual & & & & 169 & 19.0 \\
\hline upper non-manual & & & & 452 & 50.8 \\
\hline \multicolumn{6}{|l|}{ Temperament 1997-2001 } \\
\hline briskness (BR) & $0.18-0.98$ & 0.81 & 0.12 & & \\
\hline perseverance (PE) & $0.05-1.00$ & 0.54 & 0.18 & & \\
\hline sensory sensitivity (SS) & $0.28-1.00$ & 0.80 & 0.12 & & \\
\hline emotional reactivity (ER) & $0.00-1.00$ & 0.40 & 0.20 & & \\
\hline endurance $(\mathrm{EN})$ & $0.03-1.00$ & 0.56 & 0.20 & & \\
\hline activity (AC) & $0.03-0.90$ & 0.42 & 0.19 & & \\
\hline \multicolumn{6}{|c|}{$\begin{array}{l}\text { Effort-reward imbalance (ERI) and its } \\
\text { components in } 2007\end{array}$} \\
\hline ERI & $0.31-2.49$ & 0.91 & 0.29 & & \\
\hline ERI $(\log )$ & $-0.51-0.40$ & -0.06 & 0.14 & & \\
\hline rewards & $1.36-5.00$ & 3.72 & 0.61 & & \\
\hline esteem & $1.00-5.00$ & 3.77 & 0.73 & & \\
\hline job promotion & $1.00-5.00$ & 3.51 & 0.74 & & \\
\hline job security & $1.00-5.00$ & 4.01 & 0.92 & & \\
\hline effort & $1.00-5.00$ & 3.29 & 0.81 & & \\
\hline
\end{tabular}

M - mean; SD - standard deviation. 
Table 2. Pearson correlations for study variables

\begin{tabular}{lllllll}
\hline \multicolumn{1}{c}{ Correlations } & BR & PE & SS & ER & EN & AC \\
\hline Age & 0.04 & $-0.19^{* * *}$ & 0.03 & -0.03 & -0.05 & $-0.24^{* * *}$ \\
Gender & $0.14^{* * *}$ & $-0.28^{* * *}$ & $-0.16^{* * *}$ & $-0.37^{* * *}$ & $0.33^{* * *}$ & $0.07^{*}$ \\
Education & -0.02 & 0.02 & -0.00 & $-0.13^{* * *}$ & -0.04 & $0.17^{* * *}$ \\
Occupation & 0.05 & 0.00 & 0.01 & $-0.11^{* *}$ & -0.01 & $0.13^{* * *}$ \\
ERI & $-0.10^{* *}$ & $0.19^{* * *}$ & 0.00 & $0.14^{* * *}$ & $-0.14^{* * *}$ & 0.07 \\
ERI $(\log )$ & $-0.09^{* *}$ & $0.20^{* * *}$ & 0.01 & $0.14^{* * *}$ & $-0.15^{* * *}$ & $0.08^{*}$ \\
effort & -0.00 & $0.13^{* * *}$ & 0.03 & 0.01 & $-0.07^{*}$ & $0.16^{* * *}$ \\
reward & $0.18^{* * *}$ & $-0.16^{* * *}$ & 0.05 & $-0.25^{* * *}$ & $0.18^{* * *}$ & $0.11^{* *}$ \\
$\quad$ esteem & $0.15^{* * *}$ & $-0.12^{* *}$ & 0.04 & $-0.22^{* * *}$ & $0.15^{* * *}$ & $0.07^{*}$ \\
$\quad$ job promotion & $0.15^{* * *}$ & $-0.14^{* * *}$ & 0.03 & $-0.20^{* * *}$ & $0.16^{* * *}$ & $0.11^{* *}$ \\
$\quad$ job security & 0.11 & $-0.13^{* * *}$ & 0.04 & $-0.15^{* * *}$ & $0.09^{* *}$ & 0.07 \\
\hline
\end{tabular}

${ }^{*} \mathrm{p}<0.05,{ }^{* *} \mathrm{p}<0.01,{ }^{* * *} \mathrm{p}<0.001$.

Abbreviations as in Table 1.

Table 3. Linear regression analyses on temperament and ERI controlling for age, gender, education and occupation

\begin{tabular}{|c|c|c|c|c|c|c|c|c|c|}
\hline \multirow{2}{*}{ Trait } & \multicolumn{3}{|c|}{ ERI } & \multicolumn{3}{|c|}{ Effort } & \multicolumn{3}{|c|}{ Reward } \\
\hline & beta & $\mathrm{p}$ & $\%$ & beta & $\mathrm{p}$ & $\%$ & beta & $\mathrm{p}$ & $\%$ \\
\hline \multicolumn{10}{|c|}{$\begin{array}{l}\text { Effort-reward imblance (ERI) } 2007 \text { and } \\
\text { its components }\end{array}$} \\
\hline briskness & -0.09 & 0.008 & 0.8 & -0.01 & 0.779 & 0.0 & 0.17 & $<0.001$ & 2.9 \\
\hline perseverance & 0.21 & $<0.001$ & 3.7 & 0.15 & $<0.001$ & 1.9 & -0.16 & $<0.001$ & 2.3 \\
\hline sensory sensitivity & 0.01 & 0.857 & 0.0 & 0.03 & 0.321 & 0.1 & 0.05 & 0.106 & 0.3 \\
\hline emotional reactivity & 0.18 & $<0.001$ & 2.8 & 0.05 & 0.147 & 0.2 & -0.27 & $<0.001$ & 5.8 \\
\hline endurance & -0.16 & $<0.001$ & 2.1 & -0.07 & 0.034 & 0.5 & 0.19 & $<0.001$ & 3.1 \\
\hline \multirow[t]{2}{*}{ activity } & 0.05 & 0.148 & 0.2 & 0.12 & $<0.001$ & 1.4 & 0.11 & 0.002 & 1.0 \\
\hline & \multicolumn{3}{|c|}{ Esteem } & \multicolumn{3}{|c|}{ Job promotion } & \multicolumn{3}{|c|}{ Job security } \\
\hline \multicolumn{10}{|c|}{ The components of reward at work 2007} \\
\hline briskness & 0.15 & $<0.001$ & 2.2 & 0.14 & $<0.001$ & 1.9 & 0.11 & 0.001 & 1.2 \\
\hline perseverance & -0.13 & 0.001 & 1.4 & -0.13 & 0.001 & 1.4 & -0.14 & $<0.001$ & 1.6 \\
\hline sensory sensitivity & 0.04 & 0.197 & 0.2 & 0.04 & 0.214 & 0.2 & 0.05 & 0.189 & 0.2 \\
\hline emotional reactivity & -0.25 & $<0.001$ & 5.1 & -0.19 & $<0.001$ & 3.0 & -0.15 & $<0.001$ & 2.2 \\
\hline endurance & 0.17 & $<0.001$ & 2.5 & 0.16 & $<0.001$ & 2.3 & 0.08 & 0.012 & 0.7 \\
\hline activity & 0.07 & 0.045 & 0.4 & 0.11 & 0.002 & 1.0 & 0.08 & 0.025 & 0.6 \\
\hline
\end{tabular}

$\%=\Delta \mathrm{r}^{2} \times 100$. 


\section{DISCUSSION}

The aim of the present study was to examine the role of individual differences in perceptions work stress as assessed by effort-reward imbalance and its components. Higher perseveration, higher emotional reactivity, lower briskness and endurance predicted higher perceived work stress. Higher effort at work was predicted by higher perseveration and lower endurance. Higher rewards were predicted by higher briskness, higher endurance, and lower perseveration and lower emotional reactivity. Higher activity predicted both higher effort and higher rewards. The present results indicate that some temperamental characteristics may predispose the individual to work stress whereas some traits may increase resilience to stress at work.

\section{Temperament-related sensitivity to work stress}

Our hypothesis on the association between higher emotional reactivity and higher effort-reward imbalance was supported. This is in line with previous studies reporting that negative emotionality predicts higher ERI [7]. High emotional reactivity could increase stress sensitivity through a tendency to perceive stress more easily and also via inefficient stress management strategies. High emotional reactivity, in addition to other stress-related temperament traits, may increase the use of ineffective stress management styles [28-31]. Emotional reactivity has previously been related to increased use of emotion-focused, and decreased use of task-oriented stress management strategies [32]. Persons high in emotional reactivity tend to react intensely to emotional stimuli and their resilience to emotions is low, which may explain why it contributes to perception of an effort-reward imbalance. High emotional reactivity may predispose the person to stressful encounters in a work context and in its interactive systems [33]. Higher perseveration predicted a greater effort-reward imbalance. Perseveration refers to continuation and repetition of behavior after cessation of stimuli requiring this behavior. In regard to work stress, this behavioral tendency of unnecessary repetition may increase the perception of stressors and lead to repetition of inefficient stress management styles. In a work context, high perseveration could lead to inefficient working styles and difficulties in prioritizing and working with less important tasks.

\section{Temperament and resiliency to work stress}

Our hypothesis on the association between lower activity and higher ERI was not supported. This is in line with a previous study showing that activity according to Buss \& Plomin [24] did not predict work stress [7]. Instead, higher activity was linked with higher effort and rewards at work. This may imply that active employees may work with a brisk pace and engage themselves in higher efforts. At the same time, active employees may achieve set goals efficiently, and thus, be rewarded for good performance. We found that higher briskness and endurance predicted lower ERI. In addition, higher endurance predicted lower perceived efforts. The behavioral tendency of high briskness refers to reacting quickly, the ability to keep a high tempo in activities and to shift from one behavior to another when necessary. Higher endurance means the ability to react adequately in situations that require prolonged or high stimulating activity or in conditions of intensive external stimulation, e.g. not getting easily tired while working at something intensive and being able to continue working, regardless of being tired. Both these characteristics are likely to increase stress resilience in a work context that entails a large variety of demanding task- and people-related challenges. Higher briskness may be a beneficial behavioral tendency in frequently-occuring organizational changes as it may help quick adaptation to new situations. A tendency for higher endurance may increase resiliency to stressors and increase the potential for efficient stress management. Temperament seems to contribute to stress sensitivity and stress resiliency at work. An employee who is characterized by high emotional reactivity and high perseveration, and low briskness and low endurance could be sensitive to stressors 
at work because of the use of ineffective stress management and working styles. An employee characterized by an opposed constellation of temperamental characteristics (high briskness and high endurance, and low emotional reactivity and low perseveration) could be resilient to stress at work due to not getting easily tired when working intensively, the use of more efficient stress management styles and the ability to adapt to new challenges at work.

The present results indicate that some temperamental traits may predispose a person to work stress while others could buffer against work stress. These associations may partly explained by divergent associations between temperament traits and components of ERI. We found that lower briskness was associated with higher ERI, and higher briskness with higher rewards. It is possible that working at a low tempo and having difficulties in shifting from one behavior to another (lower briskness) when necessary is likely to bring out perceptions of ERI due to lower level of achievement and efficacy, and thus, potentially lower rewards at work. Perseveration was positively related to ERI because it has a positive connection with effort and negative with reward. Perseveration, i.e. the tendency to repeat irrelevant behavior or certain movements when under stress may impair work performance, increase mismanagement of tasks and result in gaining fewer rewards, and thus, contribute to an effort-reward imbalance condition. Of the components of reward, higher perseveration was related to lower esteem reward, job promotion possibilities and perceptions of job security.

\section{Temperament and rewards at work}

Higher emotional reactivity and higher perseveration predicted lower rewards at work. Higher briskness, endurance and activity and lower emotional reactivity and perseveration predicted higher perceived esteem at work, perceptions of better job promotion possibilities and experience of better job security. These temperament traits may both increase resiliency to stressors and help in achieving rewards at work.
It is possible that these traits are reflected in the employees' behavior so that they are seen energetic, flexible, resistant to fatigue and active by the employers, who are likely to appreciate these characteristics in employees in general, and through that, be transformed in actual rewards at work. In our data (results not presented here) a high income level correlates with high briskness, high endurance, high activity, low emotional reactivity and low perseveration.

\section{Limitations and methodological considerations}

Some limitations should be taken into account when interpreting the present findings. First, temperament and work stress were obtained by self-report measures. Thus, both response style and temperament-related stress sensitivity may partly explain the present findings. There are, however, several important strengths in this study. Populationbased data makes it possible to show the role of individual stress sensitivity in ERI and its components independent of age, gender, education and occupation. Our sample was representative of a wide variety of jobs and occupations, which increases the generalizability of the present findings. Work stress was measured with the original measure of effort-reward imbalance. This measure includes several sub-scales of rewards assessing different aspects of rewards (esteem, job promotion and job security), and thus, makes it possible to examine the individual differences in perceptions of different kind of rewards at work.

\section{CONCLUSIONS}

In conclusion, the present study shows that partly inherited, biological individual differences in arousability reflected in temporal and energetic characteristics of behavior contribute to work stress sensitivity. Whereas emotional reactivity and perseveration may predispose the individual to imbalance between efforts and rewards at work, briskness and endurance may protect the worker from ERI. The present results support our previous findings on individual 
differences in perceptions of work stress and extend them to an alternative conceptual model of temperament, that is, the FCB-TI model. As individual differences in temperament are related to work stress, job-based interventions concentrating solely on characteristics of work, are likely to be of limited utility. Instead, a person-centered approach which considers individual differences in work stress is likely to be a more beneficial prevention and intervention strategy when promoting work performance, job satisfaction, stress management, and personnel wellbeing.

\section{REFERENCES}

1. Van Vegchel N, de Jonge J, Bosma H, Schaufeli W. Reviewing the effort-reward imbalance model: Drawing up the balance of 45 empirical studies. Soc Sci Med 2005;60(5):1117-31.

2. Siegrist J. The measurement of effort-reward imbalance at work: European comparisons. Soc Sci Med 2004;58:1483-99.

3. Siegrist J, Marmot MG. Adverse Health Effects of HighEffort/Low-Reward Conditions. J Occup Health Psychol 1996;1(1):27-41.

4. Kivimäki M, Leino-Arjas P, Luukkonen R, Riihimäki H, Vahtera J, Kirjonen J. Work stress and risk of cardiovascular mortality: Prospective cohort study of industrial employees. BMJ 2002;325(7369):857-61.

5. Lange AH, Toon T, Kompier M, Houtman I, Bongers P. The very best Millenium: Longitudinal Research and the Demand-Control-(Support) Model. J Occup Health Psychol 2003;8(4):282-305.

6. Hintsa T, Hintsanen M, Jokela M, Pulkki-Råback L, Keltikangas-Järvinen L. Divergent influence of different type A dimensions on job strain and effort-reward imbalance. J Occup Environ Med 2010;52(1):1-7.

7. Hintsanen M, Hintsa T, Widell A, Kivimäki M, Raitakari OT, Keltikangas-Järvinen L. Negative emotionality, activity, and sociability temperaments predicting long-term job strain and effort-reward imbalance: A 15-year prospective follow-up study. J Psychosom Res 2011;71(2):90-6.
8. Lovallo WR. Stress \& health. Biological and psychological interactions. Thousand Oaks, CA: SAGE publications, Inc.; 1997.

9. McEwen BS. Protective and damaging effects of stress mediators. N Engl J Med 1998;338(3):171-9.

10. Lazarus RS, Folkman S. Stress, appraisal and coping. New York: Springer Publishing Company; 1984.

11. Strelau J. The role of temperament as a moderator of stress. In: Wachs TD, Kohnstamm GA, editors. Temperament in Context. Mahwah, NJ: Lawrence Erlbaum Associates; 2001.

12. Miller GE, Chen E, Zhou E. If it goes up, must it come down? Chronic stress and the hypothalamic-pituitary-adrenocortical axis in humans. Psychol Bull 2007;133(1):25-45.

13. Chida Y, Hamer M. Chronic psychosocial factors and acute physiological responses to laboratory-induced stress in healthy populations: A quantitative review of 30 years of investigations. Psychol Bull 2008;134(6):829-85.

14. Wachs TD. Contributions of temperament to buffering and sensitization processes in children's development. Ann N Y Acad Sci 2006;1094(1):28-39.

15. Strelau J. Temperament. A Psychological Perspective. New York: Plenum Press; 1998.

16. Hintsa T, Hintsanen M, Jokela M, Elovainio M, Raitakari OT, Keltikangas-Järvinen L. The influence of temperament on long-term job strain and its components: The Cardiovascular Risk in Young Finns Study. Pers Individ Differ 2010;49(7):700-5.

17. Hintsanen M, Puttonen S, Järvinen P, Pulkki-Råback L, Elovainio M, Merjonen P, et al. Cardiac stress reactivity and recovery of novelty seekers. Int J Behav Med 2009:16(13): 236-40.

18. Strelau J. Temperament as a regulator of behavior. After fifty years of research. New York: Eliot Werner Publications; 2010.

19. Strelau J, Zawadzki B. The Formal Characteristics of Behaviour - Temperament Inventory (FCB-TI): Theoretical assumptions and scale construction. Eur J Pers1993;7:313-36.

20. Strelau J, Zawadzki B. The Formal Characteristics of Behaviour - Temperament Inventory (FCB-TI): Validity studies. Eur J Pers 1995;9:207-29. 
21. Merecz D, Makowska Z, Makowiec-Dabrowska T. The assessment of Big Five Personality Factors and Temperament Domains as modifiers of cardiovascular response to occupational stress. Int J Occup Med Environ Health 1999;12(3):273-84.

22. Törnroos M, Hintsanen M, Hintsa T, Jokela M, PulkkiRåback L, Kivimänki $\mathrm{M}$, et al. Personality traits of the five-factor model are associated with effort-reward imbalance at work: A population-based study. J Occup Environ Med 2012;54(7):875-80.

23. Buss AH, Plomin R. Temperament: Early developing personality traits. Hillsdale, NJ: Lawrence Erlbaum Associates Inc.; 1984.

24. Buss AH, Plomin R. The EAS approach to temperament. In: Plomin R, Dunn J, editors. The study of temperament: changes, continuities and challenges. Hillsdale NJ: Lawrence Erlbaum Associates; 1986. p. 67-80.

25. Åkerblom HK, Uhari M, Pesonen E, Dahl M, Kaprio E, Nuutinen E. Cardiovascular risk in young Finns. Ann Med 1991;23(1):35-40.

26. Raitakari OT, Juonala M, Ronnemaa T, KeltikangasJärvinen L, Räsänen L, Pietikäinen M, et al. Cohort profile: the cardiovascular risk in young Finns study. Int J Epidemiol 2008;37(6):1220-6.
27. Raitakari OT, Juonala M, Kahonen M, Taittonen L, Laitinen T, Mäki-Torkko N, et al. Cardiovascular risk factors in childhood and carotid artery intima-media thickness in adulthood. JAMA 2003;290(17):2277-83.

28. Ball S, Goddard A, Shekhar A. Evaluating and treating anxiety disorders in medical settings. J Postgrad Med 2002;48(4):317-21.

29. Brown SL, Svrakic DM, Przybeck TR, Cloninger R. The relationship of personality to mood and anxiety states: A dimensional approach. J Psychiatr Res 1992;26(3):197-211.

30. Nery FG, Hatch JP, Nicoletti MA, Monkul ES, Najt P, Matsuo $\mathrm{K}$, et al. Temperament and character traits in major depressive disorder: influence of mood state and recurrence of episodes. Depress Anxiety 2009;26(4):382-8.

31. Krebs H, Weyers P, Janke W. Validation of the German version of Cloninger's TPQ: Replication and correlations with stress, coping, mood measures and drug use. Pers Individ Differ 1998;24:805-14.

32. Blecharz J, Siekanska M. Temperament structure and ways of coping with stress among professional soccer and basketball players. Biol Sport 2007;24:143-56.

33. Grant S, Langan-Fox J. Personality and the occupational stressor-strain relationship: The role of the Big Five. J Occup Health Psychol 2007;12(1):20-33.

This work is available in Open Access model and licensed under a Creative Commons Attribution-NonCommercial 3.0 Poland License - http://creativecommons.org/ licenses/by-nc/3.0/pl/deed.en. 